DOI 10.5216/ia.v46i2.67920

\title{
CRIANÇAS BOLIVIANAS NA EDUCAÇÃO PÚBLICA: MEDICALIZAÇÃO, ENQUADRAMENTOS DEFICIENTIZADORES E ESTIGMATIZAÇÕES COM BASE NO TRANSTORNO DO ESPECTRO AUTISTA
}

Marcos CezAr de Freitas

Universidade Federal de São Paulo (UNIFESP), Guarulhos, São Paulo, Brasil

\begin{abstract}
Resumo: Este artigo analisou experiências recentes de escolarização de crianças bolivianas, especificamente na cidade de São Paulo. Com registros etnográficos feitos nas pesquisas de campo, que proporcionaram participar de cenas cotidianas em três escolas públicas municipais e nos seus entornos, foi possível perceber contínuos processos de estigmatização, com ações que têm reiterado que crianças bolivianas têm propensão ao Transtorno do Espectro Autista (TEA). As categorias de análise utilizadas foram medicalização e deficientização. Com essas categorias, os excertos de fala apresentados demonstram como crianças bolivianas têm sido constantemente estigmatizadas e encaminhadas para serviços clínicos de avaliação psicológica e neurológica, desconsiderando particularidades culturais.
\end{abstract}

Palavras-chave: Bolivianos. Medicalização. Deficientização. Transtorno do Espectro Autista.

INTRODUÇÃO

Este artigo analisou a situação atual de crianças bolivianas matriculadas em três escolas públicas na cidade de São Paulo que têm sofrido os efeitos da medicalização da infância e que, de modo intenso, fazem parte da "paisagem patológica" (CHUL HAN, 2017) deste momento de profunda crise social.

Informações obtidas com pesquisa etnográfica, organizadas em cadernos de campo com sequências de registros cotidianos, possibilitaram perceber como tem sido recorrente associar particularidades étnicas e padrões culturais diversos, próprios à presença boliviana, a representações de inferioridade cognitiva, acompanhadas de percepções de transtornos e recomendações voltadas à obtenção de laudos e perícias médicas.

Nesse sentido, um estigma (GOFFMAN, 2011) se renovou e se acumulou cada vez que ações peculiares foram associadas à probabilidade de reconhecer o Transtorno do Espectro Autista (TEA), 
associação essa que não se restringe ao universo cultural boliviano, pois incide na situação concreta de outros migrantes estrangeiros e também de refugiados/as. Foi possível registrar que especificamente em relação a bolivianos/as essa estigmatização muitas vezes tornou-se uma identidade virtual (GOFFMAN, 2011, 2012) que precede a criança boliviana.

Embora a cidade de São Paulo ostente variação expressiva na diversidade cultural resultante de deslocamentos humanos, a ênfase na imigração boliviana foi aqui opção analítica em razão dos números expressivos de matrícula nas redes públicas municipal e estadual. Se processos de estigmatização e de deficientização tornaram-se observáveis com amplos e variados segmentos da multiculturalidade que caracteriza a cidade de São Paulo, de modo singular a presença boliviana proporcionou achados de pesquisa em grande proporção no que diz respeito aos temas medicalização e deficientização.

É importante registrar que em relação aos desafios das escolas públicas diante de crianças, adolescentes e jovens estrangeiros, os temas suscitados pela Educação Especial, especialmente na perspectiva da Educação Inclusiva (BRASIL, 2008), permitem utilizar a categoria deficiência em perspectiva antropológica. Esta, quando aborda reações ao chamado corpo estranho, o faz porque registra intersecções entre deficiências e questões de gênero, classe social, raça, etnia.

Especificamente essa presença estrangeira na escola pública abriu perspectiva para confirmar mais uma vez que a deficiência não é simplesmente de ordem natural, sendo imprescindível procurar apreender como e quando o cenário exerce, sobre a pessoa, efeitos deficientizadores (MURPHY, 2013), tornando-a personagem de uma trama cujo final já está presumido (GOFFMAN, 2011), reduzindo-a, assim, a objeto da ordem do medicável. ${ }^{1}$

As categorias de análise utilizadas neste artigo foram medicalização e deficientização. E as evidências de ordem empírica, como decorreram de observação participante, de registros de cenas específicas, de entrevistas, foram apresentadas no transcorrer do texto como excertos de falas etnograficamente recolhidas e, por isso, foram inseridas entre aspas, pois têm origem nas anotações de caderno de campo mencionadas.

\section{MedicALIZAÇÃo}

Com todo cuidado para evitar transposições conceituais indevidas, as situações concretas que muitas vezes conferem à criança boliviana a condição de "outro absoluto" (FREITAS, 2013) na cidade de São Paulo faz lembrar as "faixas do não-ser" propostas por Frantz Fanon (2020), referindo-se à dinâmicas de subalternização que fazem com que 
determinado corpo permaneça sempre como "presença negada" (GORDON, 2015). Trata-se de um modo de estar que permanentemente é reduzido à condição de polo oposto do aceitável. Uma questão que não se compreende fora da relação entre quem avalia (o que está) e quem é avaliado (o que chega).

Muitos autores adensaram nossa compreensão a respeito da condição de outsider (ELIAS; SCOTSON, 2004), da condição de desenraizado (SAYAD, 2014, 2018), da condição de excluído no interior (BOURDIEU, 2005), da condição de presença ignorada (GOFFMAN, 2013) que acompanham experiências de deslocamento humano. E na questão singular que foi aqui analisada, as dinâmicas de medicalização e deficientização em relação às crianças bolivianas tiveram o condão de articular fios que entreteceram vários aspectos dessas condições numa única experiência.

Medicalização é uma categoria chave nesse processo e diz respeito à crítica que emergiu na década de 1990 e início do século XXI (COLLARES, 1995; MOYSÉS; COLLARES, 1992; MOYSÉS, 2001), que desvelou o modo como queixas escolares estavam, e estão, seguidamente ignorando assimetrias sociais e diversidades culturais para afirmar que o desempenho escolar insuficiente decorre de transtornos, déficits e insuficiências de base orgânica e que, por isso, a perícia médica tem sido mobilizada para explicar "o que falta ou o que sobra" naquele que não aprende (FREITAS; GARCIA, 2019).

Angelucci e Souza (2010) levaram a efeito importante trabalho de ampliação e registro das perspectivas críticas que denunciavam a proliferação alarmante de diagnósticos de dislexia, déficits de atenção, hiperatividade, críticas essas que extrapolavam o mundo acadêmico e se articulavam com Conselhos Regionais de Psicologia e diversos coletivos relacionados à Pediatria.

Produzia-se um silenciamento pedagógico que se acomodava a uma medicalização da infância de modo mais amplo. A catalogação de comportamentos considerados incompatíveis com a produtividade escolar tornava o chão da escola um espaço cada vez mais acostumado com encaminhamentos individuais para setores e serviços especializados, visando à produção de laudos para a escola (FREITAS; GARCIA, 2019). Esses saberes periciais aplicados à educação eram (são) buscados para explicitar as bases patológicas da estranheza verificada nos modos de (não) responder da criança que não aprende (BERESFORD; CAMPBELL, 2014).

A reação crítica brasileira rapidamente se encontrou com bases críticas internacionais que igualmente resistiam à medicalização da infância e denunciavam a inacreditável epidemia de transtornos (LANDMAN, 2015). Debatedores europeus cotejavam números educacionais com números da indústria farmacêutica e demonstravam como o Código Internacional de Doenças (CID) tornou-se, nesse processo, familiar ao universo educacional. 
Naturalizava-se a presença de uma nova personagem no cenário escolar, a criança laudada (FREITAS; GARCIA, 2019), dependente de remédios para aprender, pois testes ancorados em superficial apropriação da neurologia indicavam incompatibilidades funcionais com a sincronia de ações que caracteriza a educação na forma escolar (FREITAS, 2009, 2013). Na Inglaterra isso foi chamado de "neuromania" (LANDMAN, 2015, p. 16).

Mas é importante frisar que medicalização não é uma categoria analítica que se insurge contra a administração de medicamentos. $O$ cerne de sua potência crítica está na demonstração que em dadas circunstâncias, com impressionante rapidez, a escola chega à conclusão que cabe à medicina explicitar as causas do entrave pedagógico. $O$ laudo não somente fala de alguém, mas principalmente fala por alguém (FREITAS; GONÇALVES, 2021) e em muitos casos tranquiliza docentes, afiançando que não há expectativa educacional a ser mobilizada quando a medicina já dispensou a criança de ser escolarizada (MARTINEZ; REY, 2017). Isso é medicalização.

\section{DEFICIENTIZAÇÃo}

Os chamados disability studies (DAVIS, 2014) têm configuração diversificada, mas de modo geral pode-se reconhecer que estabeleceram a arquitetura epistemológica da categoria deficientização, num processo que, desde a década de 1970, especialmente a partir dos Estados Unidos e da Inglaterra, abordou a deficiência não mais como déficit de funcionalidade (DINIZ, 2010), mas como expressão de identidade (HARAWAY, 2014), o que se somou aos estudos sobre a corporalidade plasmada na experiência, dentro das situações concretas (CSORDAS, 2016).

Se deficiência passou a ser reivindicada como aspecto identitário a mostrar-se num modo singular de estar no mundo, deficientização tornou-se um modo de abordar a condição concreta da pessoa com deficiência, assumindo que seu corpo e intelecto expressam empenhos e desempenhos em perspectiva relacional. Ou seja, as reduções de mobilidade, por exemplo, estariam relacionadas às barreiras materiais da sociedade. Já as fragilidades intelectuais, vinculadas à naturalização da chamada plena capacidade, razão de ser do binômio educar-trabalhar. As perdas sensoriais, nessa perspectiva, são deficientizadas com a projeção de um mundo ouvintista (SKLIAR, 2010) e visualista (VALLE; CONNOR, 2018) como se fosse único, sem identidades dissonantes. Estas têm sido reconhecidas apenas como percepções de ineficiência, percepções que são construídas socialmente. 
FREITAS, M. C. de

Deficientização é uma categoria que retira da dimensão orgânica a primazia de descrever o corpo histórico e remete à análise da experiência. Esta contém o processo que possibilita compreender como o sujeito singular, nos termos dos estudos culturais, torna-se alguém identificável com base em sua diferença (HALL, 2005).

Não se trata de uma categoria cuja utilização esteja relacionada a modos de inventar o deficiente e a deficiência como expressões unicamente discursivas. Sua base é o plano concreto em que as dificuldades vividas pelas pessoas não são negadas, mas estão sempre diante de tarefas que são naturalizadas (MCDERMONT; VARENNE, 2000). Uma vez naturalizadas, instituem a alteridade daquele que não as desempenha adequadamente e, ao mesmo tempo, ensejam processos que demarcam o lugar do deficiente como o contrário da eficiência.

Um enquadramento deficientizador é aquele que cumulativamente aponta indícios de inclusão indevida (FREITAS; JACOB, 2019), indicando com base no agir da própria pessoa que seu corpo está presente como ausente. As zonas de silêncio em que alguns se guardam para evitar que sejam notados e abordados, como é o caso de muitas crianças bolivianas, são referidas como evidências de alheamento.

Esse modo de registrar a presença insere aspectos de medicalização nos enquadramentos deficientizadores produzindo uma personagem tolerável, mas não escolarizável.

Por isso, é possível reconhecer nas situações que foram analisadas expressões de capacitismo (ableism na formulação dos disability studies), ou seja, reconhecer um registro de opressão que a pessoa com deficiência vive especificamente por ser percebida sempre como avesso de uma capacidade compulsória, que favorece introjetar valores de produtividade e funcionalidade como "percepção do que lhe falta" (MELLO, 2016).

Apontada como se fosse um todo incapaz a partir do suposto registro de determinada impossibilidade orgânica, a pessoa à mercê do capacitismo torna-se um sujeito circunscrito a um modo de proclamar incessantemente, com palavras ou gestos, que sua presença não está na ordem natural dos corpos feitos por inteiro, sem deficiências (CAMPBELL, 1997). E o que esse repertório analítico revelou considerando experiências recentes de escolarização de crianças bolivianas nas escolas públicas de São Paulo?

\section{CEnÁRIOS}

A presença boliviana na cidade de São Paulo é culturalmente expressiva (BRAGA, 2019), tem números crescentes (BAENINGER, 2018) e é suficientemente visível para que algumas áreas urbanas sejam reconhecidas com essa "marca cultural" (VÉRAS, 2017). 
Os números relacionados à migração estrangeira em São Paulo têm imprecisões, mas os registros ganharam maior confiabilidade com o trabalho do NEPO, o Núcleo de Estudos de População Elza Berquó, da Universidade Estadual de Campinas, cujas bases numéricas e estatísticas têm reconhecido rigor. Essa base de dados será utilizada aqui para indicar quantidades e predominâncias no tecido urbano da maior metrópole brasileira. Os dados educacionais foram recolhidos nas mesmas bases do NEPO, mas acrescidos de informações específicas relacionadas à Rede Pública de ensino da cidade, organizadas por pesquisadores/as da própria Rede (BRAGA, 2019; MASELLA, 2019), cujo processo de titulação no âmbito da pós-graduação stricto sensu tem colaborado fortemente com o adensamento das práticas de Educação Inclusiva em suas conexões com a diversidade cultural.

A presença boliviana não diz respeito somente aos fluxos urbanos com visibilidade. No âmbito dos direitos humanos é constante a preocupação com o recrutamento clandestino de mulheres bolivianas para o trabalho em confecções igualmente clandestinas, submetendoas a condições de trabalho análogas à escravidão. Essa barbárie subterrânea tocou mais diretamente as primeiras gerações de bolivianas, e embora esse dado sombrio ainda faça parte do cotidiano da cidade, pode-se reconhecer que nos últimos oito anos foi possível para muitas mulheres romper com essa situação, o que se deu com o deslocamento para postos de trabalho minimamente protegidos pela legislação laboral vigente, ainda que precários e muitas vezes subremunerados.

Essa mitigação nas bases do sofrimento social dessa população contou decisivamente com a possibilidade concreta de acesso à matrícula nas Redes Públicas mantidas pela cidade e pelo Estado de São Paulo. As garantias educacionais, assim como as alimentares e de cuidado implícitas à matrícula pública, permitiram recusar a brutalidade de algumas ofertas, persistindo na procura por oportunidades menos arriscadas. A pesquisa de campo confirmou continuamente que cada família chegada da Bolívia em São Paulo rapidamente recebe a indicação das que já estão presentes para que procurem escolas públicas, um direito que abre caminho para outros direitos.

Trata-se de um processo de aproximadamente quatro décadas. As estratégias de ocupação territorial boliviana em São Paulo ganharam delineamentos mais visíveis a partir de 1980:

Na década de 1980,1360 bolivianos vieram para São
Paulo e, em 2000,4974 , estando a maior parte na área
metropolitana (em 82 dos 96 distritos da cidade e em
23 municípios da região metropolitana). As zonas de
maior presença eram o Centro de São Paulo $(27,2 \%)$ e 
FREITAS, M. C. de

a Zona Norte $(26,4 \%)$, seguidas por Zona Leste $(19,6 \%)$, com menor presença na Zona Sul $(9,2 \%)$ e Oeste $(4,3 \%)$, conforme Xavier (2010). Os bolivianos se fixaram em áreas nas quais podiam exercer suas ocupações e obter trabalho (BRAGA, 2011 apud FERNANDEZ; MATOS, 2020, p. 126-127).

A fixação na cidade, a partir da década de 1980, seguiu critérios relacionados ao binômio trabalho-moradia e, nesse sentido, a região central da cidade foi o espaço urbano que prevaleceu. Pode-se constatar no atual cenário que a vida escolar desse universo metropolitano foi diversificada com a presença estrangeira, de modo singular, com crianças e jovens de origem étnica Quechua e Aymara.

Os dados do NEPO indicam que em 2010 a cidade de São Paulo recebeu 3.857 matrículas em cujo registro se documenta o requerimento de responsáveis bolivianos. Em 2019 esse número subiu para 7.268 e esse crescimento numérico permite constatar em 2020 que, em termos de migração estrangeira, bolivianos/as são os que mais matriculam seus filhos na Educação Infantil, no Ensino Fundamental I e II, e no Ensino Médio, só perdendo a dianteira no número de matriculados na Educação de Jovens e Adultos, cujo predomínio é de haitianos e paraguaios.

A Secretaria Municipal de Educação de São Paulo organiza sua governança administrativa e pedagógica dividindo-se em 13 Diretorias Regionais de Ensino, DREs. A tabela abaixo mostra que é possível reconhecer uma faixa infantil boliviana entre as escolas centrais (DRE Penha) e as da zona norte (DRE Jaçanã/Tremembé).

Tabela 1-Crianças bolivianas matriculadas
\begin{tabular}{|c|c|c|c|}
\hline $\begin{array}{c}\text { Matrículas } \\
\text { bolivianas }\end{array}$ & 2016 & 2017 & 2018 \\
\hline Butantã & 16 & 13 & 10 \\
\hline Campo Limpo & 20 & 25 & 16 \\
\hline Capela do Soc. & 33 & 27 & 25 \\
\hline Freguesia/Brasil & 350 & 363 & 295 \\
\hline Guaianazes & 116 & 108 & 81 \\
\hline Ipiranga & 84 & 69 & 110 \\
\hline Itaquera & 132 & 120 & 101 \\
\hline Jaçanã/Tremembé & 773 & 799 & 612 \\
\hline Penha & 705 & 666 & 51 \\
\hline Pirituba/Jaraguá & 74 & 72 & 2 \\
\hline Santo Amaro & 7 & 6 & 51 \\
\hline São Matheus & 93 & 77 & 89 \\
\hline São Miguel & 119 & 112 & 2.201 \\
\hline Total & 2.522 & 2.457 & \\
\hline
\end{tabular}

Fonte: Masella (2019). 
Na DRE Penha encontramos as escolas dos bairros Brás, Belém e Canindé, entre outros. Esses, de modo singular, registram intensa diversidade cultural de origem estrangeira, mas com uma característica singular, predomina a migração estrangeira pobre.

Nos entornos escolares dessa DRE é possível encontrar dezenas de africanos das mais variadas procedências, asiáticos, centroamericanos e sul-americanos num cenário intensamente polifônico. Temos um quadro que proporciona registrar exemplos de inserção subordinada numa sociedade que, contraditoriamente, contempla uma das mais vigorosas diversificações culturais do mundo e, ao mesmo tempo, oferece exemplos de racismo estrutural e xenofobia.

\section{A OBTENÇÃO DE INFORMAÇÕES: ESTRATÉGIAS}

Duas dimensões de pesquisa, de ordem metodológica mas também de organização interpretativa, se encontram quando está em questão discutir os temas medicalização e deficientização na experiência educacional de crianças bolivianas.

A primeira decorre daquilo que Rockwell e Ezpeleta (2007) formularam quando defenderam a importância da pesquisa etnográfica para compreender o chão da escola. Movemo-nos no âmbito do que as autoras denominam como indocumentado, pois nem todos os aspectos da cotidianidade escolar, às vezes quase nenhum, têm inteligibilidade na leitura da regulação legal que institui aquele espaço e sua razão de ser.

A segunda dimensão decorre daquilo que Goffman (2012, 2013) formulou quando propôs que prestássemos atenção nas interações face a face e na volatilidade de cenas que se apresentam e se desmancham rapidamente. Nessas, muitas vezes se surpreende o sujeito fazendo-se ou sendo feito (GOFFMAN, 2013), levando em consideração a percepção que tem de que está sendo visto, mas que, apesar disso, submerge na experiência de estar como presença ignorada (GOFFMAN, 2012).

Ambas as dimensões dizem respeito à realidade que se apreende de perto, na observação participante, no acompanhamento prolongado no tempo e continuado na presença constante nos mesmos espaços, trajetos, entornos e fluxos. Isso permite realizar entrevistas etnográficas que proporcionam uma troca contínua e cumulativa sobre o que se percebe e se presencia, com detalhes que seriam imperceptíveis nas entrevistas únicas ou na aplicação de questionários.

No caso da matéria analítica recolhida para este artigo, um esforço etnográfico de quase seis anos com professores/as, estagiários/as, coordenadores/as, mães, pais, crianças e jovens, acompanhando, perguntando, escutando, fazendo observação participativa, entrando no fluxo, repartindo a refeição, compartilhando 
a mesa permitiu flagrar o indocumentado, captar a cena irrepetível, registrar em caderno de campo a organização gestual, facial e postural dos medos, das reações, dos modos de apontar e ser apontado/a.

No processo de pesquisa longo e lento levado a efeito, mostrouse fácil e recorrente em muitas circunstâncias levantar suspeitas de que bolivianos/as seriam "propensos" ao Transtorno do Espectro Autista (TEA). Igualmente recorrente mostrou-se a partilha de opiniões que expressavam certeza de que somente um médico poderia esclarecer o comportamento da criança que se recusava a responder, mostrando, como afirmou uma professora, "que a escola não tem o que fazer quando a questão não é pedagógica".

Estas palavras entre aspas e todas as que foram utilizadas nas seções seguintes são pequenos excertos de falas registradas em cadernos de campo, e a oportunidade de retomá-las faz lembrar aspectos enfatizados por Grinker (2021) quando analisou a importância de registrar percepções culturais sobre o Transtorno do Espectro Autista (TEA). A estigmatização da criança chamada cotidianamente de "autista" não é derivada exclusivamente do uso de pressupostos de ciência, mas daquilo que culturalmente se constrói com aquela presença que é tomada sempre na dimensão da ausência.

\section{CEnAS}

Nas situações de proximidade se percebeu, por exemplo, a criança boliviana vivendo uma experiência que, na perspectiva de Goffman (2011), corresponde a passar da condição de apontado para a condição de apontável. Ou seja, tornar-se quem se aponta quando algo quer ser demonstrado. Não é casual que o autor tenha utilizado esse jogo de palavras, apontado/apontável, para demonstrar a manipulação de identidades deterioradas. São demarcações de lugar, de exterioridade, mesmo que no convívio, e de distância, mesmo que com grande proximidade.

Expressões tais como "veja como não olha" ou "note que não ergue a cabeça para responder" fazem parte de um modo de demonstrar que se reitera a ponto de naturalizar-se. O modo de ser da criança é tomado como "prova", "evidência" de que "certamente alguma medicação deve ser necessária" ou, predominantemente, "que pelo menos um pouco de autismo deve ter".

A facilidade com que foram evocadas palavras do léxico clínico somadas à sugestão rápida, trocada entre pares, de que as famílias "devem ser avisadas que existem psiquiatras e psicólogos nas UBS" (Unidades Básicas de Saúde) fazem com que escolas de bairros centrais reconhecidos pela grande presença imigrante, como Glicério, Sé, República e Bom Retiro, sejam mencionadas nos equipamentos de saúde pública como dificultadoras do cotidiano, à medida que "inundam os postos de atendimento com pedidos de avaliação". 
São hipóteses permanentemente levantadas, que mantêm em circulação predisposições a "reconhecer" no modo de agir e, especialmente, no modo de (não) responder, o que se considera "falta de algum medicamento".

A patologização da criança boliviana algumas vezes gera um circuito descritivo tão destrutivo que ela, a criança, não tem alternativa à medicalização, como, por exemplo, quando se torna possível registrar opiniões que estranham "nenhum caso de TOD entre eles", referência ao chamado Transtorno Opositor Desafiador. E quando a expectativa de TEA não se concretiza, desponta a "certeza de algum tipo de transtorno".

Essa situação não se restringe à presença boliviana, marcando socialmente crianças de outras experiências migratórias ou de refúgio internacional.

Porém, no caso específico de crianças bolivianas, especialmente porque numericamente predominantes, as formas de medicalização e deficientização visíveis no dia a dia desconsideram uma das marcas culturais mais características da infância Quechua ou Aymara, que é a organização da comunicação facial sem encarar o adulto.

Com técnicas do corpo (MAUSS, 2000), crianças bolivianas aprendem e trazem para a própria face os códigos de comunicação que se estabelecem entre gerações. Os modos de olhar etnicamente singulares dessas crianças se caracterizam pela introjeção de um universo simbólico em que são amalgamados sinais de afeto, respeito e acatamento. Trata-se de um sinal característico do que são, não daquilo que não têm em perspectiva orgânica ou neurocomportamental.

As redes públicas de educação de São Paulo têm iniciativas de acolhimento com partilhas interculturais muito expressivas. Nesse mesmo universo, docentes e dirigentes reiteradamente se posicionam contra preconceitos de ordem xenofóbica que se manifestam. Mas a aproximação permitiu registrar que não é residual a desqualificação da presença boliviana. As dinâmicas de medicalização e deficientização são evidências de problemas estruturais, de assimetrias sociais destrutivas.

A imprensa conseguiu registrar aspectos dramáticos dessa situação quando viu de perto o caso da menina síria, seguidamente reprovada e cumulativamente laudada (dislexia, déficit de atenção, deficiência de aprendizagem), cujo problema, de fato, era a distância entre o idioma árabe e o português (BRANDALISE, 2017).

Sugestivamente, a publicação que deu visibilidade à situação foi intitulada autista, não: imigrante e repercutiu nesse universo, uma vez que proporcionou a muitos/as o encontro com as próprias falas nas páginas do jornal. 
FREITAS, M. C. de

A conexão com equipamentos de saúde, especialmente as UBS, ganhou visibilidade no desvelamento dessas tramas cotidianas e um exemplo contundente foi recuperado para expor a perspectiva dos profissionais da saúde implicados. Recordaram, por exemplo, um mutirão de atendimento feito anos antes que verificou 35 crianças estrangeiras encaminhadas para perícia médica, com "suspeitas" de enquadramento no Transtorno do Espectro Autista (TEA). Nenhum dos casos se confirmou (BRANDALISE, 2017).

\section{CONSIDERAÇÕES FINAIS}

Nas dimensões de um artigo é bastante difícil priorizar exemplos para dar visibilidade às dinâmicas de medicalização e deficientização que dizem respeito à sociedade no seu todo, mas que tocam de modo singular a realidade de crianças bolivianas, pois, nas tramas cotidianas em que se encontram, até características culturais compreensíveis à luz da diversidade étnica são tomadas como evidências para argumentadores interessados em comprovar transtornos e "reconhecer traços de autismo".

Por isso, os excertos de falas recolhidas em cadernos de campo foram usados para indicar a naturalidade com a qual se interpreta que ações ou inações "só podem ser explicadas clinicamente". São falas recorrentes, autoexplicativas, que mutuamente se complementam e que, ao termo e ao cabo, resultam naquilo que Goffman (2011) denominou de manipulação da identidade deteriorada.

Essas crianças foram e são personagens de uma trama ainda mais complexa quando considerada no bojo das dificuldades enfrentadas por suas mães, muitas que nos primeiros anos de permanência enfrentaram condições de trabalho análogas à escravidão.

O quadro atual de migração estrangeira tem uma particularidade de fluxo. Ou seja, diferentemente dos momentos anteriores em que a intensidade maior de origem provinha do eixo norte-sul, o final do século $X X$ e início do século $X X I$ indicam predominância do deslocamento no eixo sul-sul global. São muitos os significados dessa particularidade, mas um dos mais expressivos é a afluência de migrantes estrangeiros demasiadamente pobres, não brancos e com diversidade étnica tão complexa quanto a diversidade nacional.

Essa particularidade se encontra com outra, decorrente de nossas lutas políticas mais expressivas. Refiro-me à Educação Inclusiva e suas garantias legais e zelo pelos Direitos Humanos. Pessoas com deficiência desde 1988 gozam dos mesmos direitos educacionais e a Educação Especial a que têm direito, quando vista na perspectiva da Educação Inclusiva (BRASIL, 2008), significa justamente o reconhecimento das intersecções que a deficiência fez e faz com questões de classe, gênero, raça e etnia. 
Por isso, mesmo as dinâmicas de medicalização e deficientização, aqui referidas de modo breve, não dizem respeito aos desafios da Inclusão, ao contrário, demonstram que ainda nos valemos dos corpos diferentes para resistirmos à diferença dos corpos. São recusas à Inclusão.

Como o tempo é de exaltação da ratio neoliberal e sua redução da governança escolar a princípios de gerencialismo e eficientismo (CARVALHO, 2020), medicalização e deficientização tornam-se experiências especialmente destrutivas para crianças bolivianas, crianças que todo etnógrafo reconhece rapidamente, pelo lindo modo de olhar.

Artigo recebido em: 27/02/2021 Aprovado para publicação em: 28/05/2021

\begin{abstract}
BOLIVIAN CHILDREN IN PUBLIC EDUCATION: MEDICALIZATION, DEFICIENT FRAMEWORKS AND STIGMATIZATIONS BASED ON AUTISTIC SPECTRUM DISORDER
\end{abstract}

ABSTRACT: This article analyzed recent schooling experiences of Bolivian children, specifically in the city of São Paulo. With ethnographic records made in the field research that allowed participating in everyday scenes in three municipal public schools and in their surroundings, it was possible to perceive continuous processes of stigmatization, with actions that have reiterated that Bolivian children are prone to Autistic Spectrum Disorder (ASD). The categories of analysis used were "medicalization" and "making deficiency". With these categories, the excerpts of speech presented demonstrate how Bolivian children have been constantly stigmatized and referred to clinical psychological and neurological assessment services, disregarding cultural particularities.

KeYWORDS: Bolivians. Medicalization. Making Deficiency. Autistic Spectrum Disorder.

NIÑOS BOLIVIANOS EN LA EDUCACIÓN PÚBLICA: MEDICALIZACIÓN, PRODUCCIÓN DE LA DISCAPACIDAD, ESTIGMATIZACIONES BASADAS EN EL TRASTORNO DEL ESPECTRO AUTISTA

RESUMEN: Este artículo analizó las experiencias escolares recientes de niños bolivianos, específicamente en la ciudad de São Paulo. Con registros etnográficos realizados en las investigaciones de campo que permitieron 
FREITAS, M. C. de.

participar de escenas cotidianas en tres escuelas públicas municipales y en sus alrededores, se pudo percibir procesos continuos de estigmatización, con acciones que han deseado comprobar que los niños bolivianos son propensos al Trastorno del Espectro Autista (ASD). Las categorías de análisis utilizadas fueron medicalización y producción de la discapacidad. Con estas categorías, los extractos del discurso presentados demuestran cómo los niños bolivianos han sido constantemente estigmatizados y remitidos a servicios de evaluación clínica psicológica y neurológica, sin tener en cuenta las particularidades culturales.

Palabras CLAVE: Bolivianos. Medicalización. Producción de la Discapacidad. Trastorno del Espectro Autista.

NOTA

1 - Ressaltamos que deficiência, neste artigo, é categoria analítica, não descrição de características orgânicas. A abordagem antropológica da questão sugere alguns cuidados. Não se trata de descrever o TEA e deduzir que pessoas "reconhecidas como exemplares" (GRINKER, 2021) correspondem àquilo que já está descrito na suma biomédica. Trata-se de compartilhar como a pesquisa etnográfica demonstrou que crianças bolivianas, meninas e meninos matriculados no primeiro ano do Fundamental I, tornaram-se pessoas "suspeitas de anormalidade".

\section{REFERÊNCIAS}

ANGELUCCI, C. B.; SOUZA, B. P. (orgs.). Medicalização de crianças e adolescentes. São Paulo, Casa do Psicólogo, 2010.

BAENINGER, R. Imigração Boliviana no Brasil. Campinas: NEPO/UNICAMP, 2018.

BERESFORD, P.; CAMPBELL, J. Personas con discapacidad, usuarios de servicios. I $n$ : BARTON, L. (org.). Superar las barreras de la discapacidad. Madrid: Morata, 2014. p. 203-215.

BOURDIEU, P. A miséria do mundo. Petrópolis: Vozes, 2005.

BRAGA, A. C. A. Imigrantes latino-americanos na escola municipal de São Paulo: sin pertinências, sino equipaje. 2019. Tese (Doutorado em Educação, Arte e História da Cultura) - Programa de Pós-Graduação em Educação, Arte e História da Cultura, Universidade Presbiteriana Mackenzie, São Paulo, 2019. 
BRAGA, F. G. Conexões territoriais e redes migratórias. Belo Horizonte: UFMG/Cedeplar, 2011.

BRANDALISE, V. H. Autista, não: imigrante. O Estado de São Paulo, São Paulo, 2017, 19 mar. 2017, EDU, p.?. Disponível em: https://educacao.estadao.com.br/noticias/geral,autista-nao-imigrante,70001705273.

BRASIL. Ministério da Educação. Secretaria de Educação Especial. Política Nacional de Educação Especial na Perspectiva da Educação Inclusiva. Brasília, DF: MEC, jan. 2008. Disponível em: http://portal.mec.gov.br/arquivos/pdf/politicaeducespecial.pdf. Acesso em: 11 jun. 2020 .

CAMPBELL, J. Growing pains, disability politics. In: BARTON L. et al. (eds.). Disability studies: past, present and future. Leeds: Disability Press, 1997. p. 78-79.

CARVALHO, M. P. Interseccionalidade: um exercício teórico a partir de uma pesquisa empírica. Cadernos de Pesquisa, São Paulo, v. 50, n. 176, p. $360-374,2020$.

CHUL HAN, B. Sociedade do cansaço. Petrópolis: Vozes, 2017.

COLLARES, C. A. L. O cotidiano escolar patologizado. 1995. Tese (Livre Docência), Faculdade de Ciências Médicas, UNICAMP, Campinas, 1995.

CSORDAS, T. Corpo, significado, cura. Porto Alegre: Editora UFRGS, 2016.

DAVIS, L. The disability studies reader. New York, Ruotledge, 2014.

DINIZ, D. O que é deficiência. São Paulo: Brasiliense, 2010.

ELIAS, N. SCOTSON, J. L. Os estabelecidos e os outsiders. Rio de Janeiro: Jorge Zahar Editor, 2004.

FANNON, F. Pele negra, máscaras brancas. São Paulo: UBU, 2020.

FERNANDEZ, C. C. G.; MATOS, M. I. S. Presença boliviana em São Paulo: cotidiano, resistência e associativismo. In: BAPTISTA, D. M. T et al. (orgs.). Migrações em expansão no mundo em crise. São Paulo, Educ, 2020. p. $123-148$ 
FREITAS, M. C. de

FREITAS, M. C. O aluno problema: forma social, ética e inclusão. São Paulo: Cortez Editora, 2009.

FREITAS, M. C. O aluno incluído na educação básica: avaliação e permanência. São Paulo: Cortez Editora, 2013.

FREITAS, M. C.; GONÇALVES, R. B. Crianças diagnosticadas com TEA na escola pública: novos desafios, velhas dicotomias. Horizontes, Campinas, v. 39, p. e021018-26, 2021.

FREITAS, M. C.; GARCIA, E. C. De diagnósticos e prognósticos: laudos na configuração de muitas experiências de escolarização. Cadernos de pesquisa, São Paulo, Fundação Carlos Chagas, v. 49, p. 316-340, 2019.

FREITAS, M. C.; JACOB. R. N. F. Inclusão educacional de crianças com deficiências: notas do chão da escola. Educação e Pesquisa, São Paulo, v. 45, online p. e186303, 2019.

GOFFMAN, E. A representação do eu na vida cotidiana. Petrópolis: Vozes, 2012.

GOFFMAN, E. Estigma: notas sobre a manipulação da identidade deteriorada. São Paulo: LTC, 2011.

GOFFMAN, E. Ritual de interação. Petrópolis, Vozes, 2013.

GORDON, L. R. What Fanon said. New York: Fordham University Press, 2015 .

GRINKER, R. R. Nobody's normal. Washington, DC: W.W.Norton, 2021.

HALL, S. Da diáspora. Belo Horizonte: Editora UFMG, 2005.

HARAWAY. D. Antropologia cyborg. Belo Horizonte: Autêntica, 2014.

LANDMAN, P. Tous hyperactifs? L'incroyable épidémie de troubles de l'attention. Paris: Éditions Albin Michel, 2015.

MARTINEZ, A. M.; REY, F. G. Psicologia, educação e aprendizagem escolar. São Paulo: Cortez Editora, 2017.

MASELLA, A. P. I. Diferença cultural, política e representações sobre inclusão escolar de imigrantes bolivianos no município de São Paulo. 2019. Dissertação (Mestrado em Educação: Currículo) - PósGraduação em Educação, PUCSP, 2019.

Inter-Ação, Goiânia, v.46, n.2, p. 645-661, maio/ago. 2021. Disponível em: <http://dx.doi.org/10.5216/ia.v46i2.67920>. 
MAUSS, M. Antropologia e sociologia. São Paulo: Cosac\&Naify, 2000.

MCDERMOTT; VARENNE, H. Culture, development, disability. In: JESSOR, R.; COLBY, A.; SHWEDER, R. (eds). Ethnography and human development. Chicago, Chicago University Press, 1996, p. 101-126.

MELLO, A. G. Deficiência, incapacidade e vulnerabilidade: do capacitismo ou a preeminência capacitista e biomédica do Comitê de Ética em Pesquisa da UFSC. Ciência saúde coletiva, Rio de Janeiro, v. 21, n. 10, p. 3265-3276, 2016.

MOYSÉS, M. A. A. A institucionalização invisível. Campinas: Mercado de Letras, 2001.

MOYSÉS, M. A. A.; COLlARES, C. A. L. A história não contada dos distúrbios de aprendizagem. Cadernos CEDES, Campinas, v. 28, n. 28, p. 31-48, 1992.

MURPHY, R. The body silent. New York: Columbia University Press, 2013.

ROCKWELL, E.; EZPELETA, J. A escola: relato de um processo inacabado de construção. Currículo sem Fronteiras, Pelotas, v. 7, n. 2, p. 131-147, Jul./Dez. 2007.

SAYAD, A. A imigração ou os paradoxos da alteridade. São Paulo: EDUSP, 2018.

SAYAD, A. The suffering of the immigrant. Massachusetts: Cambridge Press, 2014.

SKLIAR, C. A surdez. Porto Alegre: Mediação, 2010.

VALLE, J.; CONNOR, D. Ressignificando a deficiência. Porto Alegre: McGrawHill, 2018.

VÉRAS, M. P. B. Estrangeiros na metrópole: territórios e fronteiras da alteridade em São Paulo. Revista USP, São Paulo, v. 1, n. 114, p. 45-54, 2017.

Marcos Cezar de Freitas: Professor Associado Livre-Docente do Departamento de Educação da Escola de Filosofia, Letras e Ciências Humanas da Universidade Federal de São Paulo. Orientador de mestrado, doutorado e supervisor de Pós-doutorados na 
FREITAS, M. C. de

Pós-Graduação em Educação. Iniciou a carreira de professor da educação básica na escola pública em 1982 e em 1988 tornou-se professor universitário atuando, desde então, na formação de professores no Curso de Pedagogia, oferecendo unidades curriculares que abordam a construção social da infância e os fundamentos antropológicos da educação inclusiva. Foi professor visitante em universidades estrangeiras e centros de pesquisa relacionados à escolarização de crianças cronicamente enfermas.

Orcid: https://orcid.org/0000-0003-1050-415X

E-mail: marcos.cezar@unifesp.br

Este periódico utiliza a licença Creative Commons Attribution 3.0, para periódicos de acesso aberto (Open Archives Initiative - OAI). 